\title{
Kapitaalvorming by landboukoöperasies
}

\author{
W.D. Hamman \\ Nagraadse Bestuurskool, Universiteit van Stellenbosch, Posbus 610, Bellville, 7535 Republiek van Suid-Afrika \\ I.J. Lambrechts* en F.J. Mostert \\ Departement Bedryfsekonomie, Universiteit van Stellenbosch, Stellenbosch, 7600 Republiek van Suid-Afrika
}

Ontvang 3 Augustus 1987; aanvaar 5 Oktober 1987

\begin{abstract}
This article covers an analysis of capital formation of 31 representative agricultural cooperatives and follows on a previous article which covered their financial situation for the period 1975 - 1985. Concerning the capital formation, it appears that share capital did not play a major part as a source of permanent capital. Although reserves increased, it could not keep pace with the increase of the total assets. The main sources of capital formation were deferred bonuses and members' levy funds which increased more rapidly than the total assets. The total interest credited and paid on the deferred bonuses and members' levy funds were respectively $7 \%$ and $\mathbf{9 \%}$ of the opening balances. The planned rotation of both kinds of funds was relatively small in comparison with the opening balances, while the unplanned payment of the members' levy funds was larger than the planned rotation. Although rotation did not take place to a large extent, it can be a matter of concern when the funds will have to be repaid in the foreseeable future.
\end{abstract}

Hierdie artikel behels 'n finansiële beoordeling van kapitaalvorming by 31 verteenwoordigende landboukoöperasies en volg op 'n vorige artikel wat oor hulle finansiële situasie vir die periode 1975 - 1985 gehandel het. Wat kapitaalvorming betref, blyk dit dat aandelekapitaal as 'n bron van permanente kapitaal geen rol gespeel het nie. Alhoewel reserwes toegeneem het, het die betrokke toename nie tred gehou met die toename in die totale bates nie. Die belangrikste bronne van kapitaalvorming was uitgestelde bonusse en ledeheffingsfondse wat aansienlik vinniger as die totale bates toegeneem het. Totale rente gekrediteer en betaal het by die uitgestelde bonusse en ledeheffingsfondse respektiewelik $7 \%$ en $9 \%$ van die beginsaldo's bedra. Die beplande rotasie van albei soorte fondse was redelik klein in verhouding tot die beginsaldo's. Die onbeplande uitbetaling van die ledeheffingsfondse was egter aansienlik hoër as die beplande rotasie. Alhoewel die voorkoms van rotasie nie algemeen was nie, kan dit egter'n bron van kommer vir koöperasies wees wanneer die fondse terugbetaal moet word.

* Aan wie korrespondensie gerig moet word

\section{Inleiding}

Kapitaalvorming by 31 meewerkende koöperasies gedurende 1975 - 1985 is in opdrag van die SuidAfrikaanse Landbou-unie ondersoek en terselfdertyd is 'n ontleding van hulle finansiële situasie gedoen. Hierdie koöperasies het werk aan bykans 50000 mense verskaf waarvan $60 \%$ swart werknemers was. Die meewerkende ondernemings se totale bates het meer as $67 \%$ van die totale bates van alle Suid-Afrikaanse landboukoöperasies bedra en derhalwe is die $\mathbf{3 1}$ koöperasies as redelik verteenwoordigend van alle landboukoöperasies beskou in terme van totale bates.

Die finansiële ontleding (soos behandel in die vorige artikel) van die meewerkende koöperasies asook hulle meegaande kapitaalvorming moet teen die agtergrond van ' $n$ aantal belangrike veranderinge in die betrokke bedryfsomgewing beskou word. So is koöperasies vanaf 1 April 1977 belastingpligtig, maar as 'n oorgangsmaatreël is hulle toegelaat om gedurende die eerste 10 jaar (wat op 1 April 1977 gevolg het) die terugbetaling van lenings wat (volgens die Kommissaris van Binnelandse Inkomste) aangegaan is om fasiliteite te bekom vir die opberging en/of primêre verwerking van die betrokke lede se produkte, af te trek wanneer die belasbare inkomste vasgestel word.

\section{Kapitaalvorming deur koðperasies}

Kapitaalvorming behels die toename van ledebelang (dit wil sê aandelekapitaal, reserwes, uitgestelde bonusse, ledeheffingsfondse en ander ledefondse) relatief tot die totale bates. In die geval van koöperasies bestaan die probleem van die klassifikasie van uitgestelde bonusse sowel as ledeheffingsfondse. Dit word beskou asof uitgestelde bonusse en ledeheffingsfondse nie eie kapitaal is nie omdat dit terugbetaal kan word (of roteer). Die terugbetaling sowel as die rentebetalings (al dan nie) is nie besluite wat die leners (verskaffers van sulke fondse) kan neem nie, aangesien die beslissings deur die koöperasies se direkteure geneem word. Vanuit hierdie oogpunt kom uitgestelde bonusse en ledeheffingsfondse gedeeltelik ooreen met die eienskappe van voorkeuraandele en het dit dus beslis kenmerke van eie kapitaal. Dit kan dus gestel word dat uitgestelde bonusse, ledeheffingsfondse en ander ledefondse uiteraard nóg eie, nóg vreemde kapitaal is. Hierom word koöperasies se balansstaat soos volg geklassifiseer:

\section{Aandelekapitaal + reserwes $=$ eie kapitaal}

+ uitgestelde bonusse + ledeheffingsfondse (insluitend roterende heffingsfondse) + ander ledefondse $=$ ledebelang 
Tabel 1 Aanwending van die surplus van die meewerkende koöperasies (persentuele verdeling)

\begin{tabular}{lccccccc}
\hline & $\begin{array}{c}\text { Kontant- } \\
\text { bonus }\end{array}$ & $\begin{array}{c}\text { Uitgestelde } \\
\text { bonus }\end{array}$ & $\begin{array}{c}\text { Dividend } \\
\text { op aandele }\end{array}$ & $\begin{array}{c}\text { Oordrag na } \\
\text { reserwes }\end{array}$ & $\begin{array}{c}\text { Belasting- } \\
\text { verpligting }\end{array}$ & $\begin{array}{c}\text { Diverse } \\
\text { aanwendings }\end{array}$ & Totaal \\
\hline 1975 & 7,3 & 19,5 & 2,4 & 63,4 & 1,6 & 5,8 & 100 \\
1976 & 8,1 & 25,0 & 2,3 & 56,9 & 1,4 & 6,3 & 100 \\
1977 & 2,5 & 20,5 & 2,7 & 67,1 & 1,6 & 5,6 & 100 \\
1978 & 2,0 & 23,0 & 2,9 & 66,9 & 1,7 & 3,5 & 100 \\
1979 & 3,1 & 29,1 & 2,9 & 58,9 & 1,5 & 4,5 & 100 \\
1980 & 6,7 & 39,3 & 2,6 & 44,1 & 3,7 & 3,6 & 100 \\
1981 & 6,0 & 34,8 & 0,8 & 51,6 & 3,4 & 3,4 & 100 \\
1982 & 6,6 & 31,0 & 0,6 & 56,7 & 2,2 & 2,9 & 100 \\
1983 & 6,1 & 30,4 & 1,0 & 54,9 & 2,5 & 5,1 & 100 \\
1984 & 8,8 & 27,4 & 1,6 & 47,0 & 3,4 & 11,8 & 100 \\
1985 & 3,3 & 33,3 & 0,8 & 51,0 & 3,9 & 7,7 & 100 \\
\hline
\end{tabular}

Tabel 2 Verhoudingsgetalle van die kapitaalstruktuur van die meewerkende koöperasies

\begin{tabular}{|c|c|c|c|c|c|c|c|c|c|c|c|}
\hline & 1975 & 1976 & 1977 & 1978 & 1979 & 1980 & 1981 & 1982 & 1983 & 1984 & 1985 \\
\hline Ledebelang/totale bates $\times 100$ & 27,80 & 28,11 & 29,05 & 28,65 & 27,72 & 26,98 & 27,65 & 23,46 & 24,61 & 25,67 & 22,52 \\
\hline$($ Aandelekapitaal + reserwes)/totale bates $\times 100$ & 19,13 & 19,41 & 20,10 & 19,79 & 18,56 & 17,49 & 17,23 & 14,10 & 14,35 & 14,38 & 11,46 \\
\hline Lantermynlenings/totale bates $\times 100$ & 8,36 & 9,11 & 9,28 & 8,93 & 8,68 & 8,19 & 7,43 & 7,06 & 9,06 & 10,34 & 10,24 \\
\hline Vlottende laste/totale bates $\times 100$ & 63,84 & 62,77 & 61,67 & 62,41 & 63,60 & 64,83 & 64,92 & 69,48 & 66,33 & 63,98 & 67,25 \\
\hline Landbanklenings/totale bates $\times 100$ & 53,89 & 51,83 & 52,32 & 53,59 & 53,97 & 51,49 & 52,05 & 59,50 & 56,30 & 53,74 & 61,89 \\
\hline
\end{tabular}

Tabel 3 Die komponente van die meewerkende koöperasies se ledebelang: 1979 en 1984

\begin{tabular}{lrrr}
\hline & 1979 & 1984 & $\begin{array}{c}\text { Saamgestelde \% } \\
\text { groeikoers p.j. }\end{array}$ \\
\hline Aandelekapitaal & 27467 & 25039 & $-1,8$ \\
Reserwes & 336172 & 601512 & 12,3 \\
\cline { 2 - 4 } & & & \\
Eie kapitaal & 363639 & 626551 & 11,5 \\
Uitgestelde bonusse & 80873 & 244711 & 24,8 \\
Ledeheffingsfondse & 81673 & 214487 & 21,3 \\
Ander ledefondse & 14847 & 25665 & 11,6 \\
\cline { 2 - 4 } & 541032 & 1111414 & 15,5 \\
LEDEBELANG & 1951846 & 4329015 & 17,3 \\
\hline
\end{tabular}

Voordat 'n beoordeling van kapitaalvorming aan die hand van die verandering in ledebelang plaasvind, moet die aanwending van die meewerkende koöperasies se surplus eers aan die orde kom.

Volgens Tabel 1 is dit duidelik dat uitgestelde bonusse en die oordrag na reserwes ongeveer $84 \%$ van die surplus se aanwending in 1985 uitgemaak het, waardeur die likiditeit en kapitaalvorming bevoordeel kon word.

Tabelle 2 en 3 toon vervolgens die inligting met betrekking tot die kapitaalstruktuur van die betrokke ondernemings.

Terwyl ledebelang ongeveer $25,5 \%$ van die totale kapitaal uitmaak, is dit belangrik om daarop te let dat die eie kapitaal maar sowat die helfte van die ledebelang vorm. Die vlottende laste (en spesifiek Landbanklenings) is ' $n$ belangrike finansieringsvorm vir koöperasies. Aandelekapitaal as ' $n$ bron van permanente kapitaal het geen rol gespeel by kapitaalvorming nie, tewens dit het gedaal met $1,8 \%$ per jaar gedurende die periode 1979 1984. Reserwes het gestyg met $12,3 \%$ per jaar wat egter laer was as die styging in totale bates van $17,3 \%$ per jaar. Die styging in reserwes is in ' $n$ groot mate nie soseer veroorsaak deur hoë inkomste nie, maar deurdat koöperasies redelik min belasting betaal het as gevolg van verskeie fiskale toegewings gedurende die tydperk. Die groeikoers van eie kapitaal van $11,5 \%$ per jaar is dus heelwat laer as die jaarlikse groeikoers van bates van $17,3 \%$. Die toename in reserwes het ongeveer R265,3 miljoen bedra, terwyl die studie verder volgens Tabel 4 getoon het dat die aanvangs- en beleggingstoelaes, asook die toegewing vir kapitaaldelgings, oor dieselfde tydperk R230,4 miljoen bedra het wat daarop dui dat reserwes hoofsaaklik gestyg het as gevolg van die betrokke belastingtoelaes. Dit is belangrik om daarop te let dat die belastingverpligting van die betrokke koöperasies gedurende die studieperiode slegs $1,8 \%$ van die verdeelbare surplus (na rente) uitgemaak het. Die belastingpligtigheid van koöperasies het gevolglik 'n uiters geringe druk op die likiditeit van die betrokke ondernemings geplaas.

Die belangrikste kapitaalvorming het in die grysarea (nóg eie, nóg vreemde kapitaal) geskied. So het uitgestelde bonusse met $24,8 \%$ per jaar gestyg, 
Tabel 4 Rekonsiliasie tussen die verdeelbare surplus na rente en belasbare inkomste/aangeslane verlies van die meewerkende koöperasies

\begin{tabular}{|c|c|c|c|c|c|c|c|c|c|}
\hline$\left(R^{\prime} 000\right)$ & Lyne & 1979 & 1980 & 1981 & 1982 & 1983 & 1984 & Totaal & $\begin{array}{c}\text { Persentasies van } \\
\text { verdeelbare surplus } \\
\text { na rente }\end{array}$ \\
\hline Verdeelbare surplus (na rente) & $\mathbf{a}$ & 47790 & 67261 & 121639 & 119918 & 89219 & 89783 & 535610 & 100,0 \\
\hline \multicolumn{9}{|l|}{ Plus: Uitgawes wat nie vir belasting- } & 22,2 \\
\hline Minus: Dividende ontvang & c & 648 & 974 & 8753 & 1936 & 5310 & 2999 & 20620 & 3,9 \\
\hline Kapitaalwins & d & 452 & 704 & 7161 & 2119 & 4060 & 1642 & 16138 & $3, \mathbf{0}$ \\
\hline Personeelopleiding & $\mathbf{e}$ & 4 & 22 & 204 & 408 & 459 & 910 & 2007 & 0,4 \\
\hline Aanvangstoelaes & $\mathbf{f}$ & 4118 & 2970 & 3549 & 6178 & 9120 & 5812 & 31747 & 5,9 \\
\hline Beleggingstoelaes & g & 11694 & 7981 & 12238 & 21339 & 25329 & 21826 & 100407 & 18,8 \\
\hline Uitvoerderstoelae & $\mathbf{h}$ & 624 & 649 & 711 & 1758 & 2324 & 3634 & 9700 & 1,8 \\
\hline Kapitaaldelging & i & 5314 & 4901 & 12347 & 21280 & 27457 & 26979 & 98278 & 18,3 \\
\hline Gebouetoelae & j & 1011 & 1958 & 3831 & 3706 & 367 & 909 & 11782 & 2,2 \\
\hline Waardevermindering & $\mathbf{k}$ & 12190 & 12181 & 13345 & 13882 & 15539 & 14960 & 82097 & 15,3 \\
\hline Fiskale behuising van personec & eel & 202 & 39 & 115 & 323 & 296 & 182 & 1157 & 0,2 \\
\hline Ander & m & 13002 & 7766 & 7903 & 11034 & 7216 & 10796 & 57717 & 10,8 \\
\hline Totale belastingaftrekkings & $\mathbf{n}=\mathbf{c} \rightarrow \mathbf{m}$ & 49259 & 40145 & 70157 & 83963 & 97477 & 90649 & 431650 & 80,6 \\
\hline Belasbare inkomste voor bonusse & $=a+b-n$ & 13826 & 42517 & 61795 & 58373 & 18112 & 28309 & 222932 & 41,6 \\
\hline Minus: Bonusse & $\mathbf{p}$ & 21831 & 30884 & 48606 & 50959 & 31457 & 47069 & 230806 & 43,1 \\
\hline Belasbare inkomste na bonusse & $\mathbf{q}=\mathbf{o}-\mathbf{p}$ & -8005 & 11633 & 13189 & 7414 & -13345 & -18760 & -7874 & $-1,5$ \\
\hline Minus: Aangeslane verlies oorgebring & $\mathbf{r}$ & -31880 & -41810 & -33860 & -26303 & -30530 & -42567 & & \\
\hline Netto belasbare inkomste & $\mathbf{s}=\mathbf{q}+\mathbf{r}$ & -39885 & -30177 & -20671 & -18889 & -43875 & -61327 & & \\
\hline \multicolumn{10}{|l|}{ Netto belasbare inkomste bestaan uit } \\
\hline Aangeslane verliese & $\mathbf{t}$ & -41811 & -33860 & -26267 & -23073 & -45980 & -68289 & & \\
\hline \multirow[t]{2}{*}{ Belasbare inkomste } & $\mathbf{u}$ & 1926 & 3683 & 5596 & 4184 & 2105 & 6962 & 24456 & \\
\hline & $\mathbf{v}$ & -39885 & -30177 & -20671 & -18889 & -43875 & -61327 & & \\
\hline Belasting betaalbaar & $\mathbf{w}$ & 760 & 1416 & 2287 & 1665 & 608 & 3110 & 9846 & 1,8 \\
\hline
\end{tabular}

Weens die feit dat al die meewerkende koöperasies nie dwarsdeur die periode alle rekonsiliasies ingestuur het nie, balanseer die eindsaldo's van sekere jare (lyn t) nie met die beginsaldo's van die volgende jaar nie (lyn r) en is dit ook nie moontlik om sekere syfers van hierdie tabel met die van ander tabelle te balanseer nie.

Lyn $\mathrm{s}$ is die somtotaal van die medewerkers se belasbare inkomste/aangeslane verlies. Lyn $\mathrm{s}$ is hier verdeel tussen die totaal van alle aangeslane verliese (lyn $t$ ) en die totaal van alle belasbare inkomste (lyn $u$ ). Belasting betaalbaar (lyn w) moet dus gesien word relatief tot lyn $u$.

Tabel 5 Veranderinge in die uitgestelde bonusse van die meewerkende koöperasies asook toepaslike verhoudingsgetalle

\begin{tabular}{|c|c|c|c|c|c|c|c|}
\hline$\left(R^{\prime}(00)\right.$ & 1979 & 1980 & 1981 & 1982 & 1983 & 1984 & Totaal \\
\hline Beginsaldo & 61916 & 80873 & 103663 & 140012 & 179001 & 214323 & \\
\hline Uitgestelde bonusse verklaar & 16669 & 24433 & 35987 & 40235 & 37765 & 32305 & 187394 \\
\hline Rentes gekrediteer & 1778 & 2147 & 3638 & 6836 & 9000 & 10469 & 33868 \\
\hline Rotasie & -1199 & -1681 & -1359 & -3596 & -3572 & -4190 & -15597 \\
\hline Uitbetalings & -2007 & -2533 & -2445 & -5008 & -5156 & -5795 & -22944 \\
\hline Ander bewegings & 3716 & 424 & 528 & 522 & -2715 & -2401 & 74 \\
\hline Elndsaldo & 80873 & 103663 & 140012 & 179001 & 214323 & 244711 & \\
\hline Rente in kontant betaal & 1919 & 2426 & 3110 & 4760 & 5012 & 6215 & \\
\hline
\end{tabular}

Verhoudingsgetalle

Gemiddelde

Verhoudingsgetalle

Rente in kontant/ beginsaldo $\times 100$

Rente gekrediteer/ beginsaldo $\times 100$

Rotasie/ beginsaldo $\times 100$

Uitbetalings/ beginsaldo $\times 100$

$\begin{array}{rrrr}3,1 & 3,0 & 3,0 & 3,4 \\ 2,9 & 2,7 & 3,5 & 4,9 \\ -1,9 & -2,1 & -1,3 & -2,6 \\ -3,2 & -3,1 & -2,4 & -3,6\end{array}$

3,4

2,8

2,9

persentasie

$-3,2$

$-2,6$

$\begin{array}{rr}4,9 & 5,0 \\ -2,6 & -2,0\end{array}$

$-3,6$

$-2,9$

$-2,7$

$-3,0$ 
Tabel 6 Veranderinge in die ledeheffingsfondse van die meewerkende koöperasies asook toepaslike verhoudingsgetalle

\begin{tabular}{lrrrrrrr}
\hline R'000) & 1979 & 1980 & 1981 & 1982 & 1983 & 1984 & Totaal \\
\hline Beginsaldo & 63937 & 81673 & 93582 & 127184 & 162289 & 191159 \\
Bedrae gehef van lede & 15641 & 15823 & 35384 & 36728 & 30379 & 22136 & 156091 \\
Rentes gekrediteer op ledeheffing & 2559 & 2670 & 4196 & 7752 & 12639 & 13775 & 43591 \\
Rotasie & -537 & -907 & -1993 & -2529 & -4485 & -2611 & -13062 \\
Uitbetalings & -3284 & -6014 & -4349 & -7202 & -10952 & -9477 & -41278 \\
Ander bewegings & 3357 & 337 & 364 & 356 & 1289 & -495 & 5208 \\
Endacldo & 81673 & 93582 & 127184 & 162289 & 191159 & 214487 & 4205 \\
Rente in kontant betaal & 2813 & 3349 & 3743 & 3307 & 4869 & 429 \\
\hline
\end{tabular}

Verhoudingsgetalle

Gemiddelde

\begin{tabular}{lrrrrrrr} 
persentasie \\
\hline Rente in kontant/ beginsaldo $\times 100$ & 4,4 & 4,1 & 4,0 & 2,6 & 3,0 & 2,2 & 3,4 \\
Rente gekrediteer/ beginsaldo $\times 100$ & 4,0 & 3,3 & 4,5 & 6,1 & 7,8 & 7,2 & 5,5 \\
Rotasie/ beginsaldo X 100 & $-0,9$ & $-1,1$ & $-2,1$ & $-2,0$ & $-2,8$ & $-1,4$ & $-1,7$ \\
Uitbetalings/ beginsaldo x 100 & $-5,2$ & $-7,4$ & $-4,6$ & $-5,7$ & $-6,7$ & $-5,0$ & $-5,8$ \\
\hline
\end{tabular}

ledeheffingsfondse met $21,3 \%$ per jaar, ander ledefondse met $11,6 \%$ per jaar (met 'n geweegde gemiddelde van $22 \%$ ) sodat ledebelang met $15,5 \%$ per jaar kon toeneem. Vervolgens word die veranderinge in uitgestelde bonusse en ledeheffingsfondse in Tabelle 5 en 6 onderskeidelik van nader bekyk.

Die groot toename in uitgestelde bonusse tussen 1979 se R61 916000 en 1984 se R244 711000 is geleë in die gedeelte van die surplus (naamlik R187 394 000) wat nie in kontant uitbetaal is nie, maar verklaar is as 'n uitgestelde bonus, aangesien die totale rotasie en uitbetalings ongeveer gelyk is aan die totale rente gekrediteer. Rentes gekrediteer op die fonds het gemiddeld $4 \%$ op die beginsaldo's bedra. Beplande rotasie (volgens die besluite van die koöperasies se direksies) het gemiddeld $2 \%$ van die beginsaldo's bedra of te wel R15,6 miljoen oor die tydperk. Daarteenoor het die onbeplande uitbetalings (weens dood of bedanking van ' $n$ lid of weens die bereiking van ' $n$ voorgeskrewe ouderdom) R22,9 miljoen, of te wel gemiddeld 3\% van die beginsaldo's, bedra. Die totale rentes het gemiddeld $7 \%$ op beginsaldo's bedra, bestaande uit $3 \%$ in kontant en $4 \%$ wat gekrediteer is.

Die groot toename in ledeheffingsfondse oor die periode spruit voort uit die bedrae gehef van lede. Rentes betaal in kontant het gemiddeld 3,4\% en rentes gekrediteer $5,5 \%$ per jaar beloop, in totaal ongeveer $\mathbf{9 \%}$. Rotasie van ledeheffingsfondse het gemiddeld slegs $1,7 \%$ per jaar van beginsaldo's bedra en uitbetalings was heelwat hoër, naamlik $5,8 \%$ per jaar.

'n Belangrike aspek waarop gelet moet word, is die wyse of frekwensie waarop terugbetalings van die uitgestelde bonusse sowel as die ledeheffingsfondse geskied. So beloop die beplande rotasie- en onbeplande uitbetalingsbedrae as persentasies van die beginsaldo's soos volg:

\begin{tabular}{lcc}
\hline & \multicolumn{2}{c}{$\begin{array}{c}\text { Gemiddelde persentasies } \\
(1979-1984)\end{array}$} \\
\cline { 2 - 3 } & $\begin{array}{c}\text { Uitgestelde } \\
\text { bonusse }\end{array}$ & $\begin{array}{c}\text { Ledeheffings- } \\
\text { fondse }\end{array}$ \\
\hline Beplande rotasie & $2,0 \%$ & $1,7 \%$ \\
Onbeplande uitbetalings & $\mathbf{3 , 0 \%}$ & $5,8 \%$ \\
\hline
\end{tabular}

Die beplande rotasie van beide fondse is redelik laag. Aan die ander kant is die onbeplande uitbetalings van ledeheffingsfondse aansienlik hoër as die beplande rotasie. Alhoewel die persentasies redelik laag is, kan dit 'n bron van kommer vir koöperasies word as sy ledekorps se gemiddelde ouderdom reeds hoog is en die waarskynlikheid groter word dat van die fondse terugbetaal sal moet word by die dood of bedanking van 'n lid of by die bereiking van ' $n$ voorafbepaalde ouderdom.

\section{Samovatting}

Die ontleding van die kapitaalvorming wat vanaf 1979 tot 1984 plaasgevind het, het die belangrikheid van uitgestelde bonusse en ledeheffingsfondse as finansieringswyses vir koöperasies onderskryf. Uitgestelde bonusse is voordelig vir 'n koöperasie aangesien dit geen onmiddellike kontantuitvloeiing meebring nie, terwyl die bonusse vir belastingdoeleindes afgetrek kan word. Die lede moet egter belasting op die uitgestelde bonusse betaal, ongeag of dit ontvang is of nie. Word 'n huidige uitgestelde bonus van $\mathrm{R} 100$ wat oor ses jaar roteer teen 'n na-belasting verdiskonteringskoers van $10 \%$ verdiskonteer, beteken die teenswoordige waarde van R56 dat die lid steeds 'n kontantvoordeel ontvang al beloop sy marginale belastingkoers ook $50 \%$. Die groot nadeel van uitgestelde bonusse vir koöperasies is egter geleë in die 
terugbetalings daarvan tydens die afsterwe van 'n lid. Koöperasies behoort gevolglik ag te slaan op hul ledekorps se gemiddelde ouderdom aangesien 'n onbeplande uitbetaling van die fondse by die dood of bedanking van ' $n$ lid of by die bereiking van ' $n$ voorafbepaalde ouderdom, vir 'n koöperasie probleme kan meebring.

\section{Summary}

This article covers an analysis of capital formation of 31 representative agricultural cooperatives and follows on a previous article which covered their financial situation from 1975 to 1985 . As capital formation relates to the increase of the members' interest (namely share capital, reserves, deferred bonuses, members' levy funds and other members' funds) relative to the total assets of the cooperatives, each of its components had to be investigated. Share capital did not play a major part as a source of permanent capital as it actually decreased by $1,8 \%$ per annum during the period 1979 - 1984 . Although reserves increased during this period by a compounded annual rate of $12,3 \%$, the increase was lower than the annual increase of the total assets of $17,3 \%$. The main sources of capital formation were deferred bonuses and members' levy funds which increased annually by respectively 24,8 and $21,3 \%$. Total interest credited and total interest paid on the deferred bonuses and members' levy funds were respectively $7 \%$ and $9 \%$ of the opening balances. The planned rotation of both kinds of funds was respectively only $2 \%$ and $1,7 \%$ of the respective opening balances, whilst the unplanned rotation was equal to respectively $3 \%$ and $5,8 \%$ of the opening balances. It seems that rotation of the deferred bonuses and members' levy funds could become a matter of concern to the cooperatives.

Looking at the capital structure of the cooperatives, it is important to note that the tax liability of the enterprises played a vital role in capital formation, because the increase in reserves was not mainly caused by a higher income, but by the various fiscal allowances which were available to the cooperatives. The increase in reserves over the period of the investigation approximately equalled the amount of the initial and investment allowances together with the allowance for the redemption of certain loans over the same period. It is also interesting to note that the tax liability of the cooperatives concerned was only $1,8 \%$ of the distributable surplus (after interest) during the period concerned. 